\title{
Sulphaphenazole, streptomycin and sulphaphenazole combination, trimethoprim, and erythromycin in the treatment of chancroid
}

\author{
Bhushan Kumar, Vinod K Sharma, Vijay Bakaya
}

\begin{abstract}
One hundred and thirty six patients with chancroid were treated with four different treatment regimens; (A) Sulphaphenazole $1 \mathrm{~g}$ 12 hourly by mouth $\times 10$ days $(B)$ Inj streptomycin $1 \mathrm{~g}$ intramuscularly daily with sulphaphenazole $1 \mathrm{~g} 12$ hourly orally $\times 10$ days; (C) trimethoprim $200 \mathrm{mg} 12$ hourly by mouth $\times 7-10$ days, and (D) erythromycin $500 \mathrm{mg} 6$ hourly orally $\times 7-10$ days. Cure rates of $9 \%$ with sulphaphenazole alone, $48 \%$ with streptomycin and sulphaphenazole combination, $93 \%$ with trimethoprim and $100 \%$ with erythromycin were obtained. Sulphaphenazole alone or in combination with streptomycin were thus inferior in the treatment of chancroid. There is need for modification of treatment regimens recommended for chancroid in the textbooks of dermatology and venereology. Trimethoprim can be recommended as first line of treatment for chancroid in developing countries like India where resistance to trimethoprim is uncommon and erythromycin is suggested as a second line of therapy because by that time syphilis can be easily ruled out.
\end{abstract}

Chancroid is the most common cause of genital ulcers in India and accounts for $12-39 \%$ of all sexually transmitted diseases at different centres. ${ }^{1-3}$ Chancroid is mostly confined to developing countries, but epidemics have been reported from Orange County, California, United States of America ${ }^{4}$ and Holland. ${ }^{5}$ Increasing resistance of Haemophilus ducreyi to antimicrobials ${ }^{6}$ and the variable response to available treatment regimens necessitates the re-evaluation of older and prevalent regimens in addition to research for newer drugs.

Department of Dermatology, Postgraduate Institute of Medical Education and Research, Chandigarh, India

Bhushan Kumar, Vinod K Sharma, Vijay Bakaya
Patients and methods

All patients attending STD clinic between the years 1985 to 1987 with the diagnosis of chancroid based on clinical picture and negative dark ground illumination, Tzanck smear and tissue smear were considered for inclusion in the study. Patients who had received antimicrobial therapy in the last 5 days before reporting were excluded. VDRL and HIV antibody detection was carried out in all patients. Between January 1985 and December 1986, the initial 33 patients received sulphaphenazole $1 \mathrm{~g} 12$ hourly by mouth (Regimen A). Patients were reviewed after 5 days. If they showed improvement, treatment was continued for another 5 days or till the ulcer healed. If no improvement was evident injection of streptomycin $1 \mathrm{~g}$ intramuscularly daily was added and both were continued for 10 days (Regimen $B$ ). After the initial 3 months regimen $A$ was discontinued because of unacceptably higher failure rates and patients were treated with regimen $B$.

During 1987, patients were randomly allocated to trimethoprim $200 \mathrm{mg} 12$ hourly by mouth for 7-10 days (Regimen C) and erythromycin stearate $500 \mathrm{mg}$ 6 hourly orally for 7-10 days (Regimen D). Clinical details of ulcer and inguinal adenopathy (bubo) were recorded. Patients were followed weekly until the ulcers healed, when they were considered cured.

\section{Results}

One hundred and thirty six patients completed treatment and were available for follow up. All but two were men with a mean age of 27.8 years. They had had genital ulceration for 1-39 days with an average of 23 days. The majority $(70 \%)$ were unmarried and had acquired the infection from prostitutes. Thirty three patients were treated with sulphaphenazole alone, 75 with streptomycin and sulphaphenazole combination, 28 with trimethoprim and 30 with erythromycin. Thirty patients who did not respond to sulphaphenazole alone were treated with a combination of streptomycin and sulphaphenazole. Demographic details of patients treated with different regimens are shown in table 1 . VDRL and HIV antibody tests were negative in all patients. 
Table 1 Demographic data of patients treated with different treatment regimens

\begin{tabular}{|c|c|c|c|c|c|}
\hline \multirow[b]{2}{*}{$S \mathrm{No}$} & & \multicolumn{4}{|c|}{ Treatment regimens } \\
\hline & & $\begin{array}{l}A \\
S P Z\end{array}$ & $\begin{array}{l}B \\
S P Z\end{array}$ & $\begin{array}{l}C \\
T E M P\end{array}$ & $\begin{array}{l}D \\
E R Y\end{array}$ \\
\hline $\begin{array}{l}1 \\
2 \\
3 \\
4 \\
5\end{array}$ & $\begin{array}{l}\text { Number treated } \\
\text { Mean age (years) } \\
\text { Mean duration of ulcer (days) } \\
\text { Mean number of ulcers } \\
\text { No }(\%) \text { with adenitis (bubo) }\end{array}$ & $\begin{array}{l}33 \\
26 \cdot 7 \\
23 \\
2 \cdot 9 \\
18(55)\end{array}$ & $\begin{array}{l}75 \\
25 \cdot 9 \\
29 \\
2 \cdot 4 \\
45(60)\end{array}$ & $\begin{array}{l}28 \\
26 \cdot 3 \\
20 \\
2 \cdot 7 \\
9(45)\end{array}$ & $\begin{array}{l}30 \\
25 \cdot 1 \\
20 \\
3 \cdot 1 \\
15(50)\end{array}$ \\
\hline
\end{tabular}

SPZ-Sulphaphenazole; STM-Streptomycin; TMP-Trimethoprim; ERY-Erythromycin.

Table 2 Results of therapy with different treatment regimens

\begin{tabular}{llcc}
\hline & & No of patients \\
\cline { 2 - 3 } Treatment regimen & Treated & No $(\%)$ cured \\
\hline A & Sulphaphenazole $1 \mathrm{~g}$ bd $\times 10$ days & 33 & $3(9)$ \\
B & Sulphaphenazole $1 \mathrm{~g}$ bd and Inj streptomycin 1 g intramuscular, daily $\times 10$ days & 75 & $36(48)$ \\
C & Trimethoprim $200 \mathrm{mg}$ bd $\times 7-10$ days & 28 & $26(93)$ \\
D & Erythromycin stearate $500 \mathrm{mg} \times 7-10$ days & 30 & $30(100)$ \\
\hline
\end{tabular}

A cure rate of $9 \%$ was obtained with sulphaphenazole alone, $48 \%$ with streptomycin and sulfaphenazole combination, $93 \%$ with trimethoprim and $100 \%$ with erythromycin (table 2). No significant difference in the resolution of bubo was observed with various treatment schedules. Vestibular side effects were not observed with the dose of streptomycin used. Trimethoprim treatment was completely devoid of untoward effects. One patient receiving erythromycin, however, complained of epigastric pain and nausea after one week of therapy.

\section{Discussion}

Haemophilus ducreyi shows wide geographic variations in its antimicrobial susceptibility. ${ }^{7}$ It is a fastidious organism and it is not easy to culture it with the existing laboratory facilities available in developing countries like India. ${ }^{89}$ Hence it is the clinical trials with chemotherapeutic agents and not the sensitivity testing which gives information about the usefulness of the drugs.

Sulphonamides were once the mainstay of treatment of chancroid, but resistance, both plasmid and non-plasmid mediated, is now prevalent. ${ }^{10}$ However, several textbooks of dermatology ${ }^{11} 12$ and venereology ${ }^{1314}$ still continue to recommend them as the first line of treatment. We found sulphonamides alone to be singularly ineffective in the treatment of chancroid. Ramakrishnan et $a l^{15}$ also reported similar results from India.

Streptomycin alone is also recommended in the management of chancroid. ${ }^{1314}$ However, there are many reports of $H$ ducreyi being resistant to streptomycin and in fact other aminoglycosides. ${ }^{16}{ }^{17}$ Resistance to streptomycin can be stepwise or plasmid mediated, due to presence of aminoglycoside phosphotransferases, as encountered with other gram negative bacteria. ${ }^{18}$ We found streptomycin in combination with sulphaphenazole curative in less than half the cases and this treatment can no longer be recommended.

In Kenya, sulphamethoxazole $800 \mathrm{mg}$ and trimethoprim $160 \mathrm{mg}$ twice a day by mouth was found effective in $100 \%$ cases $^{19}$ and subsequently single dose treatment has been found to be equally effective in both sexes. ${ }^{2021}$ Since sulphonamides alone in our experience were totally ineffective, we used trimethroprim alone and found it effective in $93 \%$ patients. Plummer et al ${ }^{20}$ reported $92 \%$ success with trimethoprim $200 \mathrm{mg}$ twice a day for 5 days. Trimethoprim does not mask syphilis and hence can be used as first line of treatment in chancroid in countries where syphilis is endemic. However, a single dose of trimethoprim does not give acceptable cure rates and resistance may develop rapidly. ${ }^{22}$

Erythromycin, recommended as the first line of therapy in chancroid by the Center for Disease Control, Atlanta ${ }^{23}$ and WHO, ${ }^{24}$ has been found effective throughout the world, though a few resistant strains from Singapore have been reported. ${ }^{7}$ Erythromycin gave $100 \%$ success in our experience and can be recommended as the second line of treatment in developing countries because by that time syphilis can be easily ruled out.

Address for reprints: Dr Bhushan Kumar, Additional Professor, Department of Dermatology, Postgraduate Institute of Medical Education and Research, Chandigarh-160012, India

1 Kumar B, Sharma VK, Malhotra S, Bakaya V. Pattern of sexually transmitted diseases in Chandigarh. Indian $J$ Dersexually transmitted diseases in Chan
matol Venereol Leprol 1987;53:286-91.

2 Kapur TR. Pattern of sexually transmitted diseases in India. Indian J Dermatol Venereal Leprol 1982;48:23-4.

3 Jeyasingh P, Ramanaiah TBBSV, Fernandes SD. Pattern of 
sexually transmitted diseases in Madurai, India. Genitourin Med 1985;61:399-403.

4 Blackmore CA, Limpakarnjanarat K, Rigau-Perez JG, Albritton WL, Greenwood JR. An outbreak of chancroid in Orange County, California: descriptive epidemiology and disease control measures. $J$ Infect Dis 1985;151:840-4.

5 Nayyar KC, Stolz E, Michel MF. Rising incidence of chancroid in Rotterdam. Epidemiological, clinical, diagnostic and therapeutic aspects. Br J Venereal Dis 1979;55:439-41.

$6 \mathrm{McNichol} \mathrm{PJ,} \mathrm{Ronald} \mathrm{AR.} \mathrm{The} \mathrm{plasmids} \mathrm{of} \mathrm{Haemophilus} \mathrm{ducreyi}$ and Neisseria gonorrhoea. J Antimicrob Chemother 1984;14:561-73.

7 Schmid GP. The treatment of chancroid. JAMA 1986;255:1757-62.

8 Zamzachin G, Gupta U, Singh OP. A clinico-bacteriological study of chancoidal ulcers treated at AIIMS hospital, New Delhi. Indian J Pathol Microbiol 1986;29:277-83.

9 Bakaya V. Genital ulcers: clinical, bacteriological and histopatholgical correlation. MD Thesis submitted to the Faculty of Postgraduate Institute of Medical Education and Research, Chandigarh, 1987.

10 Anderson B, Albritton WL, Biddle J, Johnson SR. Common B lactamase specifying plasmid in Haemophilus ducreyi and Neisseria gonorrhoeae. Antimicrob Agents Chemother 1984;25:296-7.

11 Roberts SOB, Highet AS. Bacterial infections. In: Rook A, Wilkinson DS, Ebling FJG, Champion RH, Burton JL, eds. Textbook of Dermatology, Vol 1, 4th ed, Bombay: Oxford University Press, 1987:764-5.

12 Rudolph AH, Chancroid. In: Fitzpatrick TB, Eisen AZ, Wolff $\mathrm{K}$, Freedberg IM, Austin KF, eds. Dermatology in Internal Medicine, Vol II, 3rd ed. New York: McGraw Hill Book Company, 1987:2452-7.

13 Schofield CBS. Sexually Transmitted Diseases. 3rd ed. Edinburgh: Churchill Livingstone, 1979:216-23.
14 King A, Nicol C, Roden P. Venereal Diseases. 4th ed., London: English Language Book Society, 1986:251-7.

15 Ramakrishnan KR, Aggarwal SK, Arora PN, Ramachandra S. Comparison of different non-treponemocidal drug regimens in chancroid. Indian J Sex Trans 1988;9:29-31.

16 Ranjan VS, Sng EH. Streptomycin resistant Haemophilus ducreyi. Lancet 1982;ii: 1043.

17 Sturm AW, Zanen HC. Drug of choice of chancroid. Lancet 1983;i:125.

18 Sanson-LE, Pors MJ, Casin IM, Collartz E. Plasmid mediated aminoglycoside phosphotransferases in Haemophilus ducreyi. Antimicrob Agents Chemother 1985;28:315-9.

19 Fast MV, Nsanze H, D'Costa LJ et al. Antimicrobial therapy of chancroid an evaluation of 5 treatment regimens correlated with in vitro sensitivity. Sex Trans Dis 1983;10:1-6.

20 Plummer FA, Nsanze H, D'Costa LJ, Karasira D, Mac Lean IW, Ellison RH, Ronald AR. Single dose therapy of chancroid with trimethoprim sulfametrole. $N$ Engl J Med 1983;309: 67-71.

21 Dylewski J, D'Costa LJ, Nsanze H, Ronald AR. Single dose therapy with trimethoprim-sulfametrole for chancroid in females. Sex Trans Dis 1986;13:166-8.

22 Taylor DN, Pitarangsi C, Echeverria P, Panikabutra K, Suvongse $C$. Comparative study of ceftriazone and trimethoprim sulfamethoxazole treatment of chancroid in Thailand. $J$ Infect Dis 1985;152:1002-6.

23 Centers for Disease Control. Sexually transmitted diseases treatment guidelines 1982 MMWR 1982;31(Suppl 2).

24 World Health Organisation. Current treatment and control of sexually transmitted diseases. World Health Organsation (Geneva) WHO/VDT 1983;89:433.

Accepted for publication 16 November 1989 